Preprint

UCRL-JC-140386-REV-1

\title{
Numerical Modeling of enhanced Nitrogen Dissolution During Gas Tungsten Welding
}

\section{T. A. Palmer}

This article was submitted to $59^{\text {th }}$ Electric Furnace Conference, Phoenix, Az., November 11-14, 2001

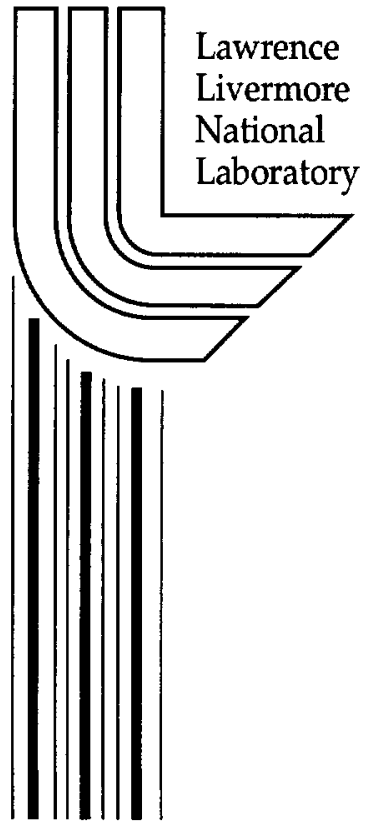

\section{August 17, 2001}




\section{DISCLAIMER}

This document was prepared as an account of work sponsored by an agency of the United States Government. Neither the United States Government nor the University of California nor any of their employees, makes any warranty, express or implied, or assumes any legal liability or responsibility for the accuracy, completeness, or usefulness of any information, apparatus, product, or process disclosed, or represents that its use would not infringe privately owned rights. Reference herein to any specific commercial product, process, or service by trade name, trademark, manufacturer, or otherwise, does not necessarily constitute or imply its endorsement, recommendation, or favoring by the United States Government or the University of California. The views and opinions of authors expressed herein do not necessarily state or reflect those of the United States Government or the University of California, and shall not be used for advertising or product endorsement purposes.

This is a preprint of a paper intended for publication in a journal or proceedings. Since changes may be made before publication, this preprint is made available with the understanding that it will not be cited or reproduced without the permission of the author.

This work was performed under the auspices of the United States Department of Energy by the University of California, Lawrence Livermore National Laboratory under contract No. W-7405-Eng-48.

This report has been reproduced directly from the best available copy.

Available electronically at http://www.doc.gov/bridge

Available for a processing fee to U.S. Department of Energy

And its contractors in paper from

U.S. Department of Energy

Office of Scientific and Technical Information

P.O. Box 62

Oak Ridge, TN 37831-0062

Telephone: (865) 576-8401

Facsimile: (865) 576-5728

E-mail: reports@adonis.osti.gov

Available for the sale to the public from

U.S. Department of Commerce

National Technical Information Service

5285 Port Royal Road

Springfield, VA 22161

Telephone: (800) 553-6847

Facsimile: (703) 605-6900

E-mail: orders@ntis.fedworld.gov

Online ordering: http://www.ntis.gov/ordering.htm

OR

Lawrence Livermore National Laboratory

Technical Information Department's Digital Library

http://www.llnl.gov/tid/Library.html 


\title{
NUMERICAL MODELING OF ENHANCED NITROGEN DISSOLUTION DURING GAS TUNGSTEN ARC WELDING
}

\author{
Todd A. Palmer \\ Lawrence Livermore National Laboratory \\ P.O. Box 808, L-355 \\ Livermore, CA 94551 \\ United States \\ (925) 423-8468 \\ palmer18@llnl.gov
}

Key Words: nitrogen dissolution, arc welding, iron, plasma, mathematical modeling

\section{INTRODUCTION}

Nitrogen concentrations far in excess of Sieverts' Law calculations and as high as $0.2 \mathrm{wt} \%$ have been obtained in steel welds during arc welding. ${ }^{1-7}$ Such high concentrations of nitrogen in the weld metal can originate from a variety of sources, depending on the welding operation in question. One such mechanism involves the interaction between the surrounding atmosphere, which is about $80 \%$ nitrogen, and the plasma phase above the weld pool. Impingement of the surrounding atmosphere into the arc column, which is primarily composed of an inert shielding gas, can be due, in part, to insufficient shielding of the weld metal. In other cases, nitrogen can be purposefully added to the shielding gas to enhance the microstructural evolution of the weld metal.

The mechanisms responsible for enhanced nitrogen concentrations are of significant interest. In both arc melting and welding operations, a plasma phase exists above the liquid metal. This plasma phase, which is composed of a number of different species not normally observed in gas-metal systems, significantly alters the nitrogen absorption reaction in liquid iron and steel. ${ }^{7-15}$ Monatomic nitrogen $(N)$ is considered to be the species responsible for the observed enhancements in the nitrogen concentration. This role for monatomic nitrogen is based on its significantly higher solubility in iron with partial pressures many orders of magnitude less than that for diatomic nitrogen. ${ }^{4,16,17}$

It has also been proposed that the total amount of nitrogen present in the liquid metal is the balance of two independent processes. ${ }^{10,18-21}$ Monatomic nitrogen is absorbed through the interface between the arc and the liquid metal. Once a saturation level is reached at any location on the metal surface, nitrogen is then expelled from the surface of the liquid metal. This expulsion of nitrogen from the weld pool surface occurs via a desorption reaction, in which bubbles form at the surface and other heterogeneous nucleation sites in the liquid melt. These bubbles are filled with nitrogen gas, which has been rejected from the liquid iron. Outside the arc column, the nitrogen in solution in the iron is in equilibrium with diatomic nitrogen rather than monatomic nitrogen, which dominates the arc column.

Models based on the role of the plasma phase in producing these enhanced nitrogen concentrations have also been developed. For example, Gedeon and Eagar ${ }^{22}$ have proposed that the diatomic gas introduced into the 
plasma phase in the arc column partially dissociates at a temperature higher than that at the sample surface. The monatomic species is then transported to the liquid metal surface, where it is absorbed at the temperature on the liquid metal surface. Mundra and DebRoy ${ }^{16}$ have used this same methodology to develop a semi-quantitative model to describe the temperature at which the diatomic gas dissociates in the plasma phase. In the twotemperature model, ${ }^{16,22}$ a hypothetical temperature, $T_{d}$, equal to the temperature at which the equilibrium thermal dissociation of diatomic nitrogen produces the partial pressure of monatomic nitrogen in the plasma, is defined. This dissociation temperature is in a range of 100 to $300 \mathrm{~K}$ higher than the temperature at the metal surface, $T_{s}$, and is a measure of the partial pressure of the atomic nitrogen in the plasma. This methodology provides an order-of-magnitude agreement between the calculated and experimental nitrogen concentrations but does not strictly provide a capability for predicting the nitrogen concentration.

No quantitative means for predicting the nitrogen concentration in the weld metal currently exists. In developing a quantitative model, it must be recognized that nitrogen dissolution into the weld pool is intimately tied to several simultaneously occurring physical processes. These processes include the formation of various nitrogen species in the plasma phase above the weld pool, reactions at the interface between the plasma phase and the weld pool surface, and the transport of nitrogen within the weldment by convection and diffusion. A mathematical model, which combines calculations describing each of these processes into a single model, has been developed here. The validity of this model has also been tested by comparing the modeling results with those from a series of GTA welding experiments with pure iron.

\section{MODEL DEVELOPMENT}

Plasma Phase Calculations- During GTA welding, the interaction between the tungsten electrode and the inert shielding gas produces a plasma phase above the weld pool. This plasma phase is characterized by electron temperatures between 3000 and $20000 \mathrm{~K}$ and consists of different ionized and neutral species. Various Ar- $\mathrm{N}_{2}$ gas mixtures have been used here in the GTA welding of pure iron samples. In order to calculate the resulting nitrogen concentration in the weld metal, the partial pressure of monatomic nitrogen above the weld pool must be known. A methodology to calculate the number densities of species present in the plasma phase for a variety of pure gases and gas mixtures has been presented in a previous study. ${ }^{17}$ This methodology is based on the assumption of local thermodynamic equilibrium (LTE) in the plasma phase. Under LTE conditions, both quasineutrality and ideal gas law behavior are assumed to be dominant.

The individual species densities ( $\mathrm{Ar}, \mathrm{Ar}^{+}, \mathrm{Ar}^{++}, \mathrm{N}_{2}, \mathrm{~N}_{2}^{+}$, and $\mathrm{N}^{+}$) in $\mathrm{Ar}-\mathrm{N}_{2}$ gas mixtures are analyzed here. The ionization reactions for both $\mathrm{Ar}$ and $\mathrm{N}_{2}$ species are generally defined by the Saha-Eggert relation, ${ }^{23-25}$ which is shown below for the ionization of an Ar atom:

$$
\begin{aligned}
& \mathrm{Ar} \rightarrow \mathrm{Ar}^{+}+\mathrm{e}^{-} \\
& \frac{\mathrm{n}_{\mathrm{e}^{n} \mathrm{Ar}^{+}}}{\mathrm{n}_{\mathrm{Ar}}}=\frac{2\left(2 \pi \mathrm{m}_{\mathrm{e}} \mathrm{kT}\right)^{3 / 2}}{\mathrm{~h}^{3}} \frac{\mathrm{Z}_{\mathrm{Ar}^{+}}}{\mathrm{Z}_{\mathrm{Ar}}} \mathrm{e}^{-\left(\varepsilon_{\mathrm{Ar}}\right) / \mathrm{kT}}
\end{aligned}
$$

where $n_{e}$ is the electron density, $n_{i}$ is the number density for each of the respective gaseous species, $m_{e}$ is the rest mass of an electron, $k$ is the Boltzmann Constant $\left(1.38 \times 10^{-23} \mathrm{~J} \mathrm{~K}^{-1}\right), \mathrm{T}$ is the electron temperature $(\mathrm{K}), \mathrm{h}$ is Planck's Constant $\left(6.63 \times 10^{-34} \mathrm{~J} \mathrm{~s}\right), Z_{i}$ is the partition function for each gaseous species, and $\varepsilon_{i}$ is the ground 
state energy for the species of interest. The partition functions ${ }^{23-26}$ are based on the various energy levels of each atomic or molecular species and provide insight into the fundamental nature of the species of interest. Values of the partition functions, which vary with the electron temperature, are calculated elsewhere. ${ }^{17}$

In addition to the ionization reactions occurring in the plasma phase, the dissociation of diatomic molecules into atomic species is also considered in Equations (3) and (4).

$$
\begin{aligned}
& \mathrm{N}_{2}(\mathrm{~g}) \rightarrow 2 \mathrm{~N}(\mathrm{~g}) \\
& \mathrm{K}=\frac{\mathrm{p}_{\mathrm{N}}^{2}}{\mathrm{p}_{\mathrm{N}_{2}}}=\frac{(\mathrm{P})^{2}\left(\mathrm{X}_{\mathrm{N}}\right)^{2}}{(\mathrm{P}) \mathrm{X}_{\mathrm{N}_{2}}}=\mathrm{P} \frac{\left(\mathrm{X}_{\mathrm{N}}\right)^{2}}{\mathrm{X}_{\mathrm{N}_{2}}}=\frac{\left(\mathrm{n}_{\mathrm{N}}\right)^{2}}{\mathrm{n}_{\mathrm{N}_{2}}}\left(\frac{\mathrm{RT}}{\mathrm{N}_{\mathrm{A}}}\right)
\end{aligned}
$$

where $P$ is the total system pressure (atm), $p_{N}$ is the partial pressure of monatomic nitrogen, $p_{N_{2}}$ is the partial pressure of diatomic nitrogen, $X_{N}$ and $X_{N_{2}}$ are the mole fractions of $N$ and $N_{2}$, respectively, $n_{N}$ and $n_{N_{2}}$ are the number densities $\left(\mathrm{m}^{-3}\right)$ for $\mathrm{N}$ and $\mathrm{N}_{2}$, respectively, $\mathrm{R}$ is the gas constant $\left(8.314 \mathrm{~J} \mathrm{~mol}^{-1} \mathrm{~K}^{-1}\right)$, and $\mathrm{N}_{\mathrm{A}}$ is Avogadro's number $\left(6.022 \times 10^{24} \mathrm{~mol}^{-1}\right)$. At temperatures commonly used for conventional materials processing, the free energy values are available and the value of $\mathrm{K}$ can be easily calculated. On the other hand, accurate thermodynamic data are not readily available for the high temperatures commonly found in the welding plasma. A recourse is to calculate the necessary data, which have been presented elsewhere. ${ }^{17}$

The charge and mass of the system must also be balanced. The charge balance, which is based on the principle of quasineutrality, is expressed by the sum of electrons produced by the ionization reactions. The conservation of mass in the system is based on ideal gas law. These equations are then solved simultaneously to obtain values for each species present in the plasma.

Nitrogen Absorption at the Weld Metal Surface- Nitrogen is introduced into the weldment only at the top surface. In the area underneath the arc column and defined by the liquid weld pool, the absorption of monatomic nitrogen is dominant. The monatomic nitrogen partial pressure is defined by the electron temperature distribution above the weld pool. In the region outside the arc column and above the solid portion of the weldment, the nitrogen dissociation reaction is minimal, and the absorption of diatomic nitrogen species in solid iron is predominant. In this region, the diatomic nitrogen partial pressure outside the arc column is determined using the relation for the thermal dissociation of the diatomic nitrogen at the temperature on the weld pool surface.

The residual nitrogen concentration in the weld pool is governed by a balance between the nitrogen absorption and desorption reactions. In order for nitrogen to leave the weld metal, a certain level of nitrogen concentration in the liquid metal must be reached. Above these nitrogen concentration levels, nitrogen leaves the weld metal. Nitrogen concentrations are therefore not allowed to exceed this level, thus controlling the onset of nitrogen desorption.

\section{Nitrogen Transport in the Weldment}

Governing Equations - The absorption of nitrogen on the weld pool surface and the transport of nitrogen in the weld pool are based on the temperature and fluid flow fields in the weldment. These values are calculated using a transient, three-dimensional control volume based computational procedure ${ }^{27-28}$ in which the equations for the conservation of mass, momentum, energy, and the nitrogen concentration are solved. These equations are formulated in a coordinate system $(\zeta, y, z, t),{ }^{27}$ in which the heat source and the molten metal under it are fixed in space, and the material enters and leaves the computational domain at the welding velocity. ${ }^{29-30}$ The equations 
of conservation of mass, momentum and energy are defined in previous work. ${ }^{28-30}$ The weld pool geometry reaches steady-state shortly after the start of welding. Thus, the transient terms from the governing equations are removed and the solution becomes a steady state one. On the other hand, the nitrogen concentration calculations are time dependent. Therefore, the governing equations for momentum and energy are solved separately from the equation of conservation of nitrogen concentration. A non-uniform grid $(96 \times 25 \times 26)$ has been used to solve all of these equations and to account for the large temperature gradients commonly present in welding operations.

Fluid flow in weld pool is also turbulent in nature, ${ }^{36-38}$ and in order to take this into account, the local viscosity values are increased. ${ }^{27,28,39-42}$ This effective viscosity is the sum of the molecular viscosity, which is a physical property of the fluid, and the turbulent viscosity, which is based on the nature of the flow in a given system. An effective thermal conductivity is determined similarly. The turbulent thermal conductivity and viscosity are related by the turbulent Prandtl number, $\mathrm{Pr}_{t}$, which is held constant at a value of 0.9 for these calculations. The transport of nitrogen within the weld pool is also enhanced with the presence of turbulence. In order to take into account the presence of turbulence, the diffusion coefficient of nitrogen is enhanced. By enhancing the diffusion coefficient, the ratio between the effective and theoretical diffusivity for nitrogen in liquid iron $\left(D_{\text {eff }} / D_{N}\right)$ is defined. The nitrogen diffusion coefficient in liquid iron is enhanced by a constant factor $(20)$ here.

Boundary Conditions- The boundary conditions for the steady-state solution are shown in Fig. 2 . In the solid portion of the weldment, all velocities are zero, and the initial temperature is $298 \mathrm{~K}$. The top surface of the solution geometry is flat, and there is no flow of liquid out of the face. The gradients of $u$ and $v$ are tied to the spatial gradient of the surface tension, and $w$ is zero. Along the plane of symmetry through the weld pool center, similar conditions are prevalent.

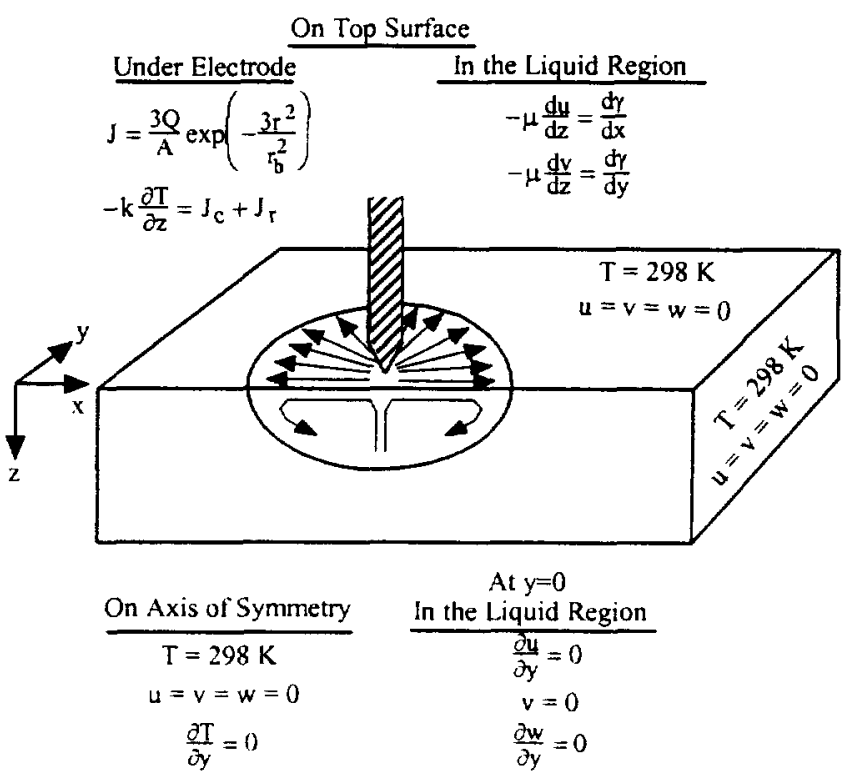

Fig. 1: Summary of boundary conditions used in the mathematical model for solution of heat transfer and fluid flow in the weldment. ( $Q$ is the energy input, $A$ is the area of the arc column, $J_{c}$ is the energy flux due to conduction, $J_{r}$ is the energy flux due to radiation) 
The distribution of heat flux from the arc is assumed to be Gaussian. The energy flux from the arc to the weld metal is prescribed on the top surface by the relationship shown in Fig. 2. The maximum efficiency ${ }^{43}$ of the GTA welding process is assumed to be approximately $80 \%$. Heat transfer in the liquid metal portion of the weldment on the top surface is defined by the relationship shown in Fig. 2. On the sample surfaces, the temperature is initially set at $298 \mathrm{~K}$, and is maintained at this level at the surfaces far from the heat source. On the plane of symmetry, the temperature gradient is set to zero. An initial nitrogen concentration of $20 \mathrm{ppm}$, which is the initial nitrogen concentration in the base metal used in the experiments, is assumed throughout the weldment. Along the plane of symmetry, the nitrogen concentration gradient (dc/dy) is zero. Nitrogen concentrations at locations away from the sample surface and the weld pool are prescribed to be equal to the initial nitrogen concentration of the base metal $([\mathrm{N}]=20 \mathrm{ppm})$.

Experimental Methods- A series of autogenous, bead-on plate GTA welds (150 A, $25 \mathrm{~V})$ have been made on iron samples $(0.002 \mathrm{C}, 0.031 \mathrm{Al}, 0.0022 \mathrm{Cr}, 0.2 \mathrm{Mn}, 0.003 \mathrm{Mo}, 0.006 \mathrm{Ni}, 0.002 \mathrm{~N}, 0.002 \mathrm{O}, 0.006 \mathrm{P}, 0.001 \mathrm{~S}$, $0.009 \mathrm{Si}$ ) . Higher purity samples have been used in order to avoid the effects of additional alloying elements on the nitrogen solubility. The distance between the electrode tip and the workpiece, defined as the arc length, is maintained constant throughout the welding runs $(0.0032 \mathrm{~m})$, and a $2 \%$ thoriated tungsten electrode with a diameter of $0.000238 \mathrm{~m}$ has been used. In order to avoid contamination, the welding chamber has been backfilled with argon prior to welding to purge the system of unwanted environmental impurities. Throughout the duration of each welding run, a total pressure of $0.1 \mathrm{MPa}$ has been maintained within the experimental chamber. Controlled ultra high purity (UHP) argon-nitrogen gas mixtures are used to shield the weld pool. The effects of changes in the travel speed $(0.00846 \mathrm{~m} / \mathrm{sec}$ and $0.00423 \mathrm{~m} / \mathrm{sec})$ and shielding gas composition ( 0 to $20 \% \mathrm{~N}_{2}$ additions) on the resulting nitrogen concentration are studied. After the completion of each weld line, samples $(0.000635 \mathrm{~m}$ thick) are removed from the weld line. The weld metal nitrogen concentration in each of these samples is then measured using vacuum fusion analysis.

\section{RESULTS AND DISCUSSION}

Nitrogen in the Plasma Phase- Number densities for the species present in several Ar- $\mathrm{N}_{2}$ gas mixtures over a range of electron temperatures have been calculated. Fig. 2(a) shows a plot of the calculated species density distribution for an Ar-5\% $\mathrm{N}_{2}$ gas mixture at atmospheric pressure. Argon species dominate across the range of temperatures, given the much higher fraction of argon in the gas mixture. Among the nitrogen species, diatomic nitrogen dominates at temperatures below $6000 \mathrm{~K}$, where the extent of dissociation and ionization is low. Above approximately $7000 \mathrm{~K}$, monatomic nitrogen is the dominant species, and $\mathrm{N}^{+}$dominates as the temperature is increased above $17000 \mathrm{~K}$. The general trends shown in this figure are representative of all gas compositions studied here.

The monatomic nitrogen partial pressure above the weld pool is based on the electron temperature distribution and the accompanying monatomic nitrogen species density in the plasma phase. Temperatures in the arc column have been found to range from approximately 3000 to $20000 \mathrm{~K}$, with higher temperatures near the electrode and lower temperatures at weld pool surface..$^{44.50}$ As the weld pool surface is approached, temperatures significantly lower than those found in the arc column are encountered. ${ }^{51}$ Calculations of the monatomic nitrogen partial pressures are shown in Fig. 2(b) as a function of the electron temperature typical of the region adjacent to the weld pool surface. Monatomic nitrogen partial pressures vary by up to five orders of magnitude over 
this temperature range. Therefore, even small variations in the temperature can significantly affect the amount of monatomic nitrogen, thus further complicating the modeling of the nitrogen dissolution reaction.

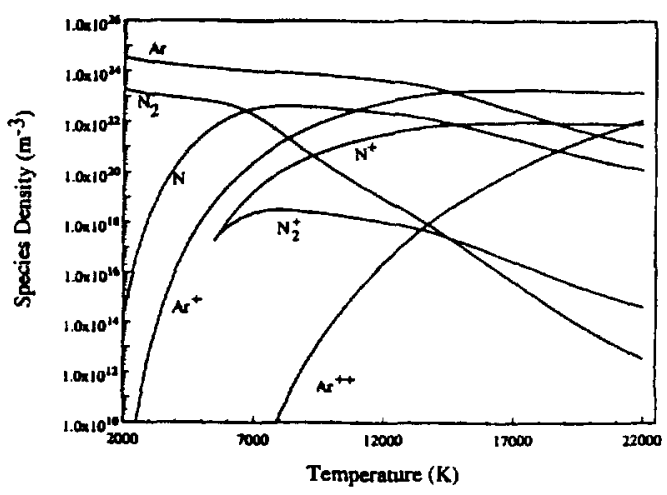

(a)

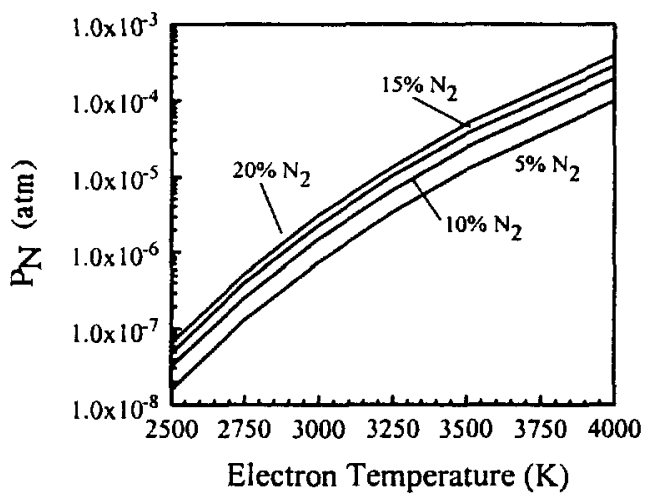

(b)

Fig. 2(a\&b). Plots of (a) computed species densities for an Ar-5\% $\mathrm{N}_{2}$ gas mixture as a function of temperature and (b) changes in monatomic nitrogen partial pressures with temperature.

Temperature and Fluid Flow Fields in the Weld Pool- Fig. 3 shows the calculated steady-state temperature and fluid flow fields in the weld pool in three dimensions. At both travel speeds, the elongated pool shapes and temperature fields are typical of welds with a moving heat source. The effect of the change in travel speed is evident. For example, the calculated peak temperatures and weld pool widths and depths are greater at the slower travel speed. The calculated dimensions generally correspond with the experimental weld pool shape, even though the modeled weld pool is somewhat wider. In each case, a strong outward flow of liquid from the weld pool center to the weld pool periphery is observed at each travel speed. This behavior is consistent with previous modeling ${ }^{27}$ and experimental ${ }^{52}$ work.
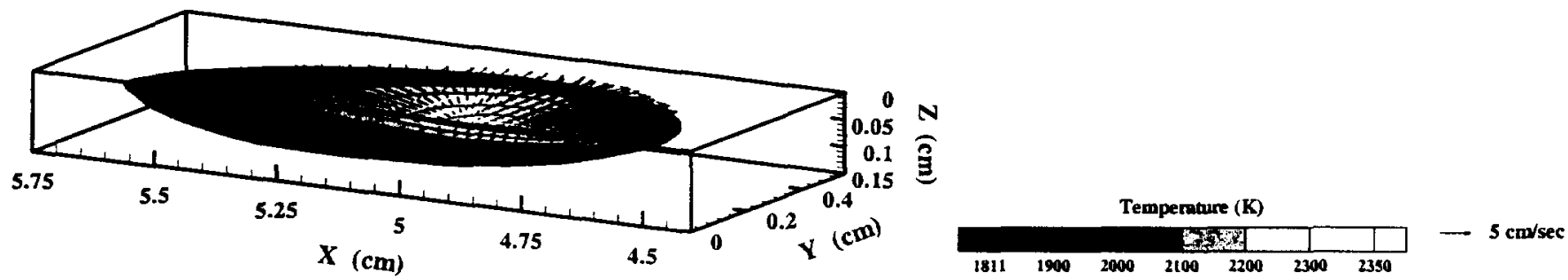

Fig. 3: Modeling results for both temperature and at a travel speed of $0.00847 \mathrm{~m} / \mathrm{sec}$.

The temperature distribution on the weld pool surface, shown in Fig. 4, contributes to the amount of nitrogen absorbed from the plasma phase. A rather symmetrical temperature distribution, with the peak temperatures present under the heat source and decreasing temperatures at the weld pool periphery is shown. Changes in the temperature distribution on the weld pool surface affect the resulting nitrogen absorption and the spatial distribution of nitrogen concentrations. 


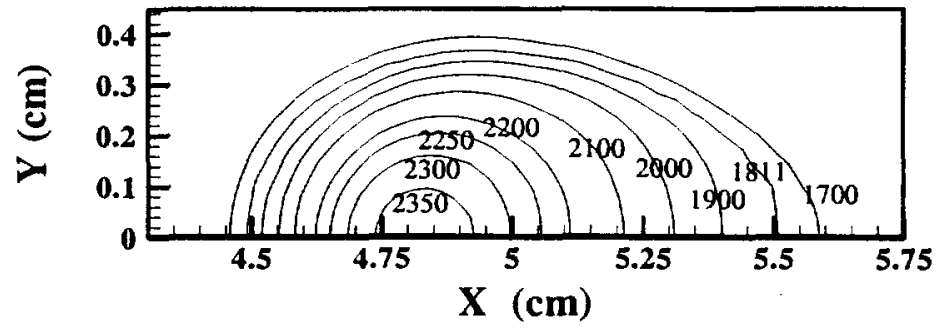

Fig. 4: Computed temperature $(\mathrm{K})$ profiles on the weld pool surface for a travel speed of $0.00847 \mathrm{~m} / \mathrm{sec}$.

Nitrogen Surface Concentrations -Nitrogen concentrations on the weld pool surface are based on both the monatomic nitrogen partial pressures above the weld pool and the weld pool surface temperatures. The monatomic nitrogen partial pressures, in turn, are based on the electron temperatures present in the plasma phase and the nitrogen addition to the shielding gas. Variation in the electron temperatures in the plasma phase with increasing distance from the energy source, with a maximum temperature located directly under the heat source and a minimum value at the solid-liquid interface, are assumed. These electron temperature distributions are used as a basis for determining the monatomic nitrogen partial pressures above the weld pool. Even small changes in the electron temperature can produce significant changes in the monatomic nitrogen partial pressure, as shown in Fig. 5(a). The corresponding nitrogen concentrations on the weld pool surface are shown in Fig. 5(b). At the weld pool center, the nitrogen concentrations are their lowest, even though the monatomic nitrogen partial pressures are at a maximum. As the weld pool periphery is approached, the nitrogen concentrations reach a value at which nitrogen desorption occurs. This nitrogen concentration is defined by Sieverts' Law at the surface temperature and a nitrogen partial pressure of $0.1 \mathrm{MPa}{ }^{4,16-17}$ The nitrogen distribution is indicative of monatomic nitrogen species in iron, where nitrogen solubility decreases with an increase in the temperature. $^{21}$

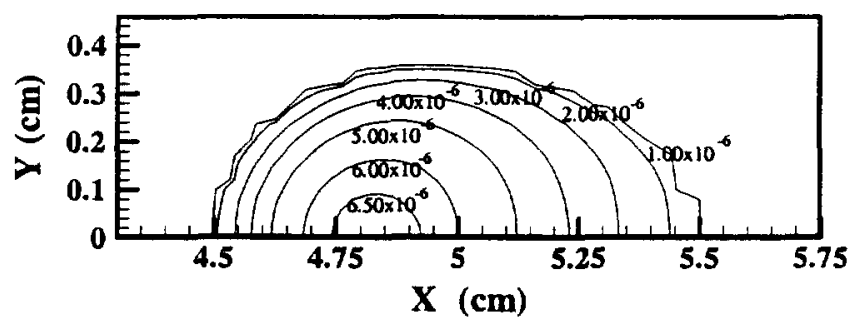

(a)

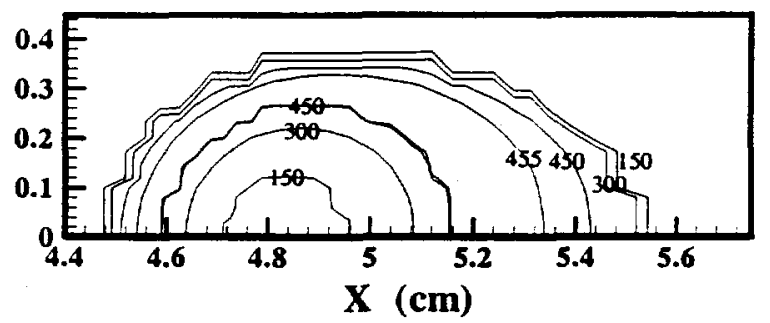

(b)

Fig. 5(a\&b): (a) monatomic nitrogen partial pressure (MPa x 10) and (b) Nitrogen concentration (ppm) distribution for a travel speed of $0.00847 \mathrm{~m} / \mathrm{sec}$ and a $10 \% \mathrm{~N}_{2}$ addition to the shielding gas.

Nitrogen Concentrations in the Weld Pool -Nitrogen absorbed on the weld pool surface is transported to the weld pool interior by convection and diffusion. Three-dimensional, transient calculations of the nitrogen concentrations in the weld pool have been performed here. A typical nitrogen concentration distribution in the weld pool is shown in Fig. 6. In this figure, the transient nitrogen concentrations are superimposed on the steady state weld pool shape, giving an indication of how the nitrogen concentration varies. 

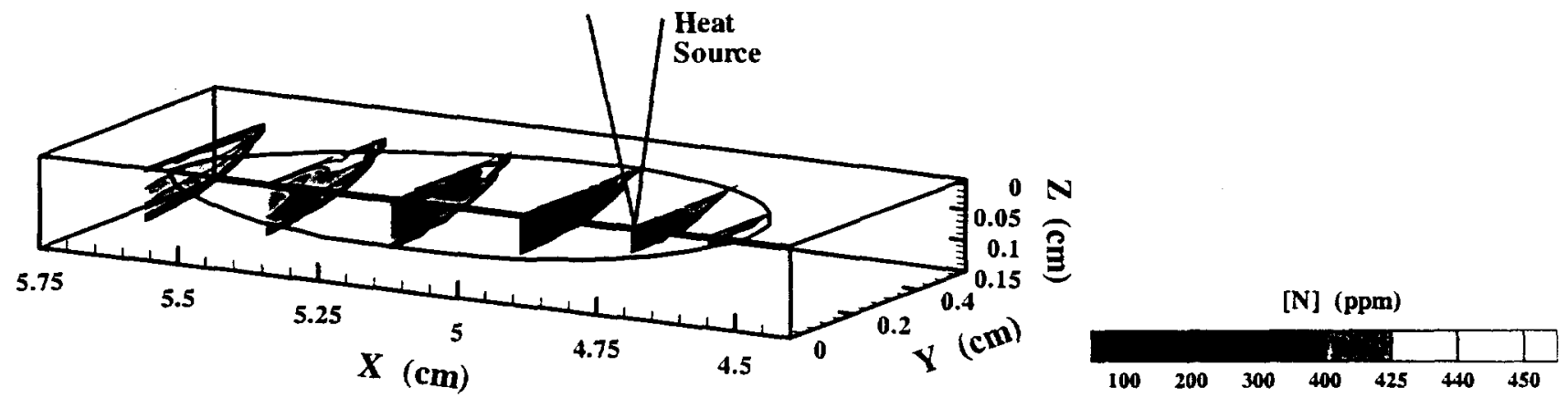

Fig. 6: Three dimensional plot of nitrogen concentrations in the weld pool at several times for a travel speed of $0.00847 \mathrm{~m} / \mathrm{sec}$. ( $10 \% \mathrm{~N}_{2}$ addition to the shielding gas)

Nitrogen concentrations evolve along the length of the weld pool up to the point of solidification. In the early stages, lower nitrogen concentrations are observed in the center of the weld pool, resulting from the lower monatomic nitrogen solubility in liquid iron at higher temperatures. It is also apparent that the transport of nitrogen is the result of the fluid flow patterns in the weld metal. As the weld pool evolves, nitrogen is transported from the outer edges to the interior of the weld pool. Once the weld pool solidifies, the nitrogen is trapped in place. The nitrogen concentration in the weld pool is then computed by integrating the nitrogen concentrations across the solidified weld pool cross section. At each travel speed, the average nitrogen concentration generally increases with an increase in the nitrogen partial pressure. These values are compared with experimental results, which fall in a range of 2.7 to 4.7 times greater than Sieverts' Law calculations at temperatures of $2000 \mathrm{~K}$ and $2500 \mathrm{~K}$ and the same nitrogen partial pressures.

Different nitrogen additions to the shielding gas result in increases in the nitrogen concentrations in the weld pool interior. Nitrogen additions between 15 and $20 \%$ result in nitrogen concentrations in the weld pool approaching the level required for nitrogen desorption. Changes in the electron temperature distribution also affect the calculated nitrogen concentration distributions. Fig. 7(a) shows a nitrogen concentration distribution across the solidified weld pool cross section for a $10 \% \mathrm{~N}_{2}$ addition to the shielding gas and electron temperatures between 3250 and $3000 \mathrm{~K}$. Electron temperatures between 2750 and 2500 are assumed in Fig. 7(b). The highest nitrogen concentrations are located in the weld pool center and decrease as the former liquid-solid interface is approached. An analysis of the resulting nitrogen concentration distributions over this electron temperature range shows that electron temperatures above $3000 \mathrm{~K}$ produce similar nitrogen concentrations in the weld pool. Therefore, only electron temperatures between 3000 and $3250 \mathrm{~K}$ are considered in the remaining analysis.

Nitrogen concentrations have been calculated over a range of electron temperatures and compared with the experimental results. For each set of electron temperatures and travel speed, the calculated nitrogen concentrations increase with the nitrogen addition to the shielding gas. With higher electron temperatures, the increase becomes less and the nitrogen concentrations become similar. Electron temperatures at these levels produce nitrogen concentrations on the weld pool surface at or near the level at which nitrogen desorption is considered, allowing no more nitrogen to enter the weld pool. On the other hand, when the calculated nitrogen concentrations are compared with the experimental results, they fall below the experimental values for each condition considered. Therefore, there are other conditions to be taken into account in the calculations. 


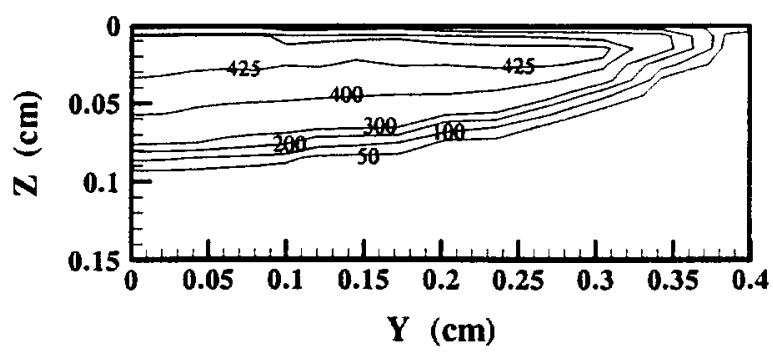

(a)

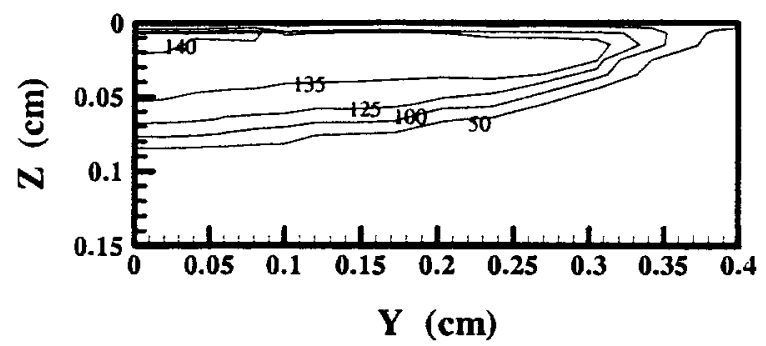

(b)

Fig. 7(a\&b): Nitrogen concentration (ppm) distributions in the weld pool for electron temperatures between (a) 3250 and $3000 \mathrm{~K}$ and (b) 2750 and $2500 \mathrm{~K}$ with a $10 \% \mathrm{~N}_{2}$ addition to the shielding gas.

Nitrogen Desorption Effects- Since the calculated nitrogen concentrations are less than the experimental results, other mechanisms are contributing to the nitrogen dissolution reaction. One such mechanism is the desorption of nitrogen from the solidifying weld metal. In this model, a limit is placed on the nitrogen concentrations in the weld pool to define the level of nitrogen at which desorption occurs. The choice of this level is rather arbitrary, and previously has been set equal to the Sieverts' Law calculations for nitrogen in liquid iron with a nitrogen partial pressure of $0.1 \mathrm{MPa}$. Since this value is insufficient to explain the experimental results, the effects of changing this level of nitrogen concentration value are examined here.

The effect of the gas concentration in the liquid metal on the resulting desorption of gas has been noted elsewhere. ${ }^{53-54}$ During the decarburization of iron melts, $([\mathrm{C}]+[\mathrm{O}] \rightarrow \mathrm{CO}(\mathrm{g}))$, carbon concentrations can reach levels up to 15 times higher than those predicted by equilibrium calculations. The removal of carbon from the melt through the evolution of $\mathrm{CO}(\mathrm{g})$ from liquid iron has been found to be dependent upon the availability of nucleation sites for bubble formation within the melt. As the number of heterogeneous nucleation sites increases, the level of carbon supersaturation in the melt decreases. In this case, nitrogen desorption $\left(2[\mathrm{~N}] \rightarrow \mathrm{N}_{2}(\mathrm{~g})\right)$ is tied to a supersaturation of nitrogen in the liquid iron. Several nitrogen supersaturation levels ranging between 25 and $100 \%$ higher than the nitrogen solubility calculated by Sieverts' Law calculations for a nitrogen partial pressure of $1 \mathrm{~atm}$ have been analyzed. In Fig. 8(a\&b), the effects of nitrogen supersaturation enhancements of $75 \%$ at electron temperatures between 3250 and $3000 \mathrm{~K}$ on the resulting nitrogen concentration distributions on the weld pool surface and in the weld pool interior, respectively, are shown.

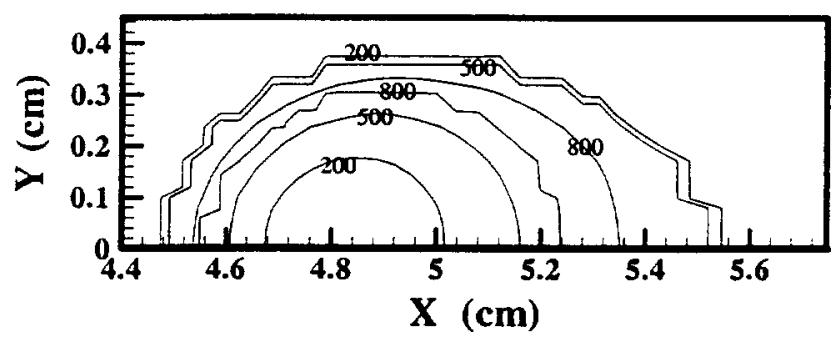

(a)

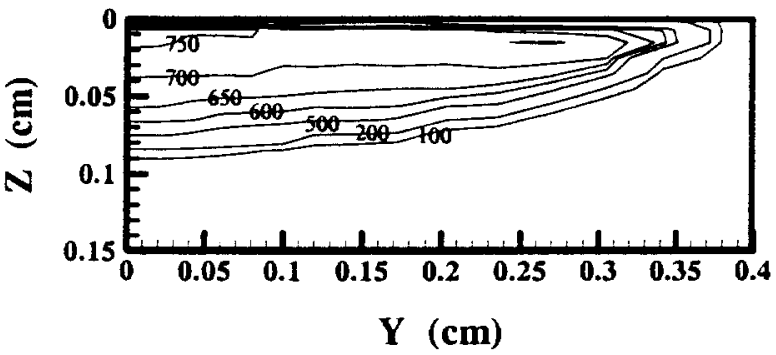

(b)

Fig. 8(a\&b): Calculated nitrogen concentration (ppm) distributions (a) on the weld pool surface and (b) in the weld pool interior for an enhancement in the of nitrogen supersaturation of 1.75 . 
With a $75 \%$ enhancement in the maximum allowable nitrogen concentration on the weld pool surface, significantly higher nitrogen concentrations are present on the weld pool surface and in the weld pool interior. For example, nitrogen concentrations on the weld pool surface reach levels approaching $800 \mathrm{ppm}[\underline{\mathrm{N}}]$ near the weld pool periphery and $750 \mathrm{ppm}[\underline{\mathrm{N}}]$ in the weld pool interior. Similar conditions are observed with each level of nitrogen supersaturation examined at each travel speed and with each nitrogen addition to the shielding gas.

A comparison between the calculated nitrogen concentrations and the experimental results is shown in Fig. $9(a \& b)$ as a function of the nitrogen additions to the shielding gas for each travel speed. The calculated results for enhancements between 50 and $75 \%$ fall in the same range as the experimental results. For each level of enhancement, the calculated nitrogen concentrations increase with greater additions of nitrogen to the shielding gas. This generally linear increase in the calculated nitrogen concentration provides a similar trend to that observed experimentally. Therefore, the consideration of nitrogen desorption through an increase in the allowable nitrogen concentrations on the weld pool surface provides a necessary component to this model and enhances the understanding of the nitrogen dissolution reaction.

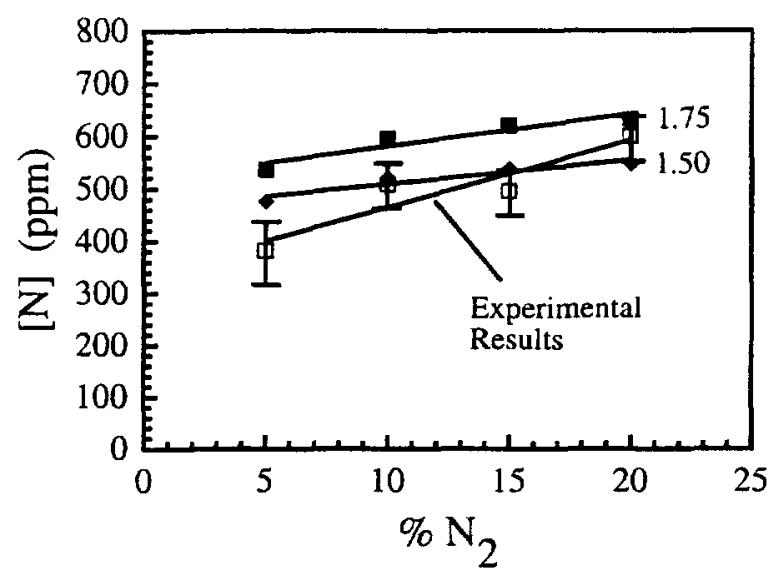

(a)

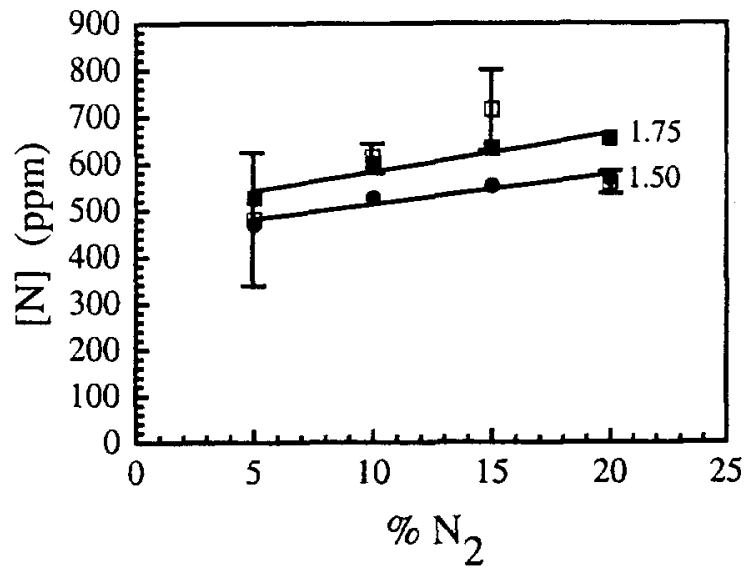

(b)

Fig. 9(a\&b): Comparison between experimental and calculated nitrogen concentrations for travel speeds of (a) $0.00847 \mathrm{~m} / \mathrm{sec}$ and (b) $0.00423 \mathrm{~m} / \mathrm{sec}$.

\section{SUMMARY AND CONCLUSIONS}

A model to calculate the nitrogen concentration in the weld metal during the GTA welding of iron has been developed here. Nitrogen concentrations in the weld pool are based on the combination of calculations involving the plasma phase above the weld pool, the interface between the weld pool surface and the plasma phase, and the weldment interior. Monatomic nitrogen partial pressures are calculated as a function of the electron temperatures in the plasma phase, and nitrogen concentrations on the weld pool surface are based on both the monatomic nitrogen partial pressure and the weld pool surface temperatures. Once absorbed at the weld pool surface, nitrogen is then transported to the weldment interior predominantly by convection. The presence of turbulence in the weld pool, which is taken into account by increasing the nitrogen diffusion coefficient, further enhances the transport of nitrogen. Nitrogen desorption, which occurs via bubble formation at the liquid metal surface, is characterized by a supersaturation of nitrogen in the weld metal and is also considered in this model. 
To test the validity of this model, several autogenous GTA welding experiments in pure iron have been performed at two travel speeds with a number of nitrogen additions to the argon shielding gas. Nitrogen concentrations have also been measured in each weld and compared with the modeling results. The general shape and size of the experimental and modeled weld pools are similar. Both the modeling and experimental results produce nitrogen concentrations between 2.7 and 4.7 times higher than Sieverts' Law calculations for a temperature of $2000 \mathrm{~K}$ and nitrogen partial pressures between 0.005 and $0.020 \mathrm{MPa}$. When the modeling and experimental results are compared, both results are equivalent in magnitude for a given set of welding parameters and follow similar trends with changes in the nitrogen addition to the shielding gas and the travel speed.

The modeling calculations also display several features, which contribute to these results. Electron temperatures in the plasma phase adjacent to the weld pool in a range around $3000 \mathrm{~K}$ are found to produce levels of monatomic nitrogen sufficient to produce nitrogen concentrations in the weld pool equivalent to the experimental results. Levels of nitrogen supersaturation between 50 and $75 \%$ higher than the equilibrium nitrogen concentration are required to produce the nitrogen concentrations equivalent to the experimental results. The incorporation of turbulence in the calculations is also a key component in the final results.

\section{ACKNOWLEDGEMENTS}

This work has been supported by the United States Department of Energy, Office of Basic Energy Sciences, Division of Materials Science, under Grant No. DEFG02-84ER45158 and under the auspices of the U.S. Department of Energy by University of California, Lawrence Livermore National Laboratory under contract No. W-7405-Eng-48. The financial support provided by the American Welding Society Foundation and the Navy Joining Center in the form of an AWS Graduate Research Fellowship is also acknowledged.

\section{REFERENCES}

1. S. Kou: Welding Metallurgy, New York, John Wiley and Sons, 1987, 61-63.

2. C.J. Allum: Bulletin of Welding Research Council, 369, Dec. 1991-2, 68-84.

3. P.D. Blake: Weld. Res. Int., 9 (1), 1979, 23-56.

4. T.A. Palmer, K. Mundra, and T. DebRoy: in Mathematical Modelling of Weld Phenomena 3, ed. by H. Cerjak, London, The Institute of Materials, 1997, 3-40.

5. T. Kuwana and H. Kokawa: Trans. Jap. Weld. Soc., 1986, 17(1), 20-26.

6. T. Kuwana, H. Kokawa, and K. Naitoh: Trans. Jap. Weld. Soc., 1990, 21(2), 85-91.

7. T.A. Palmer and T. DebRoy: Weld. J., 1996, 75(6), 197-s - 207-s.

8 F. Elliott and M. Gleiser: Thermochemistry for Steelmaking I, Reading, MA, Addison-Wesley Publishing Co., 1963, 75 .

9. H.E. McGannon, ed.: The Making, Shaping and Treating of Steel, 9th edition, United States Steel Corporation, 1971, 330-331.

10. G. den Ouden and O. Griebling: in Recent Trends in Welding Science and Technology, ed. S.A. David and J.M. Vitek, Materials Park, OH, ASM International, 1990, 431-435.

11. F.S. Death and D.A. Haid: U.S. Patent No. 3,257,197, 1966. 
12. V.I. Lakomskii and G.F. Torkhov: Soviet Physics-Doklady, 1969, 13(11), 1159-1161.

13. J.D. Katz and T.B. King: Metall. Trans. B, 1989, 20B, 175-185.

14. T. Kuwana and H. Kokawa: Trans. Jap. Weld. Soc., 1988, 19(2), 12-19.

15. P.D. Blake and M.F. Jordan: J. Iron Steel Inst., 1971, 209(3), 197-200.

16. K. Mundra and T. DebRoy: Metall. and Mat. Trans., 1995, 26B, 149-157.

17. T.A. Palmer and T. DebRoy: Sci. Tech. Weld. Join., 1998, $\underline{3}(4), 190-203$.

18. M. Uda and S. Ohno: Trans. Nat. Res. Inst. Metals, 1978, 20(6), 358-365.

19. K. Takeda and Y. Nakamura: Trans. ISIJ, 1978, 18, 641-647.

20. S. Ohno and M. Uda: Trans. Nat. Res. Inst. Metals, 1981, 23(4), 243-248.

21. M. Uda and T. Wada: Trans. Nat. Res. Inst. Metals, 1968, 10(2), 21-33.

22. S.A. Gedeon and T.W. Eagar: Weld. J., 1990, 69, 264s-271s.

23. G.J. Dunn and T.W. Eagar: Met. Trans. A, 1986, 17A, 1865-1871.

24. K.S. Drellishak, D.P. Aeschliman, and A.B. Cambel: Phys. of Fluids, 1965, $8(9), 1590-1600$.

25. K.S. Drellishak, C.F. Knopp, and A.B. Cambel: Phys. of Fluids, 1963, 6(9), 1280-1288.

26. J.D. Fast: Philips Res. Rep., 1947, 2 , 382-398.

27. K. Mundra, T. DebRoy, and K.M. Kelkar: Num. Heat Trans. A, 1996, 29, 115-129.

28. K. Mundra, J.M. Blackburn, and T. DebRoy: Sci. Tech. Weld. Joining, 1997, 2(4), 174-184.

29. S. Kou and Y.H. Wang: Met. Trans. A, 1986, 17A, 2265-2270.

30. C. Prakash, M. Sammonds, and A.K. Singhal: Int. J. Heat Mass Transfer, 1987, 30(12), 2690-2694.

31. E.T. Turkdogan: in BOF Steelmaking, ed. by R.D. Pehlke, et al., Iron and Steel Soc. AIME, New York, 1975, 1-190.

32. M.L. Wasz and R.B. McLellan: Scripta Met. et. Mat., 1993, 28, 1461-1463.

33. P. Grieveson and E.T. Turkdogan: Trans. Met. Soc. AIME, 1964, 230, 1604-1609.

34. K. Schwerdtfeger: Trans. Met. Soc. AIME, 1967, 239, 134-138.

35. W.T. Lankford, N.L. Samways, R.F. Craven, and H.E. McGannon, ed.: The Making, Shaping, and Treating of Steel, $10^{\text {th }}$ ed., United States Steel Corporation, 1985.

36. R.T.C. Choo and J. Szekely: Weld J., 1994, 73, 25s - 31s.

37. K. Hong, D.C. Weckman, and A.B. Strong: Trends in Welding Research, ed. by H.B. Smartt, J.A. Johnson, and S.A. David, Materials Park, OH, ASM International, 1996, 399-404.

38. M. Malinowski-Brodnicka, G. den Ouden, and W.J.P. Vink: Weld J., 1990, 69, 52s - 59s.

39. K. Mundra, T. DebRoy, T. Zacharia, and S.A. David: Weld. J., 71, 1992, 313s - 320s.

40. M.H. Davies: Numerical Modelling of Weld Pool Convection in Gas Metal Arc Welding, Ph.D. Thesis, The University of Adelaide, South Australia, 1995.

41. W. Pitscheneder, M. Gruböck, K. Mundra, T. DebRoy, and R. Ebner: in Mathematical Modelling of Weld Phenomena 3, ed. by H. Cerjak, London, The Institute of Materials, 1997, 41-63.

42. B.E. Launder and B.D. Spalding: Mathematical Models of Turbulence, Academic Press, New York, NY, 1972.

43. W.H. Giedt, L.N. Tallerico, and P.W. Fuerschbach: Weld. J., 1989, 68(1), 28-s - 32-s. 
44. R.T.C. Choo, J. Szekely, and R.C. Westhoff: Met. Trans. B, 1992, 23B, 357-369.

45. J.F. Key, J.W. Chan, and M.E. Mcllwain: Weld. J., 1983, 62(7), 179s-184s.

46. A.E.F. Gick, M.B.C. Quigley, and P.H. Richards: J. Phys. D: Appl. Phys., 1973, 6 , 1941-1949.

47. J. Wendelstorf, I. Decker, H. Wohlfahrt, and G. Simon: in Mathematical Modelling of Weld Phenomena 3 , ed. by H. Cerjak, London, The Institute of Materials, 1997, 848-897.

48. G.N. Haddad and A.J.D. Farmer: Weld. J., 1985, 64(12), 399s-342s.

49. A.J.D. Farmer and G.N. Haddad: J. Phys. D: Appl. Phys., 1984, 17, 1189-1196.

50. M.B.C. Quigley, P.H. Richards, D.T. Swift-Hook, and A.E.F. Gick: J. Phys. D: Appl. Phys., 1973, 6 , 22502258.

51. H.A. Dinulescu and E. Pfender: J. Appl. Phys., 1980, s1(6), 3149-3157.

52. W. Pitscheneder, R. Ebner, T. Hong, T. DebRoy, K. Mundra, and R. Benes: in Mathematical Modelling of Weld Phenomena 4, ed. by H. Cerjak, London, The Institute of Materials, 1998, 3-25.

53. C. Bodsworth: Physical Chemistry of Iron and Steel Manufacture, London, Longmans, 1963.

54. R.G. Ward: An Introduction to the Physical Chemistry of Iron \& Steel Making, London, Edward Arnold Publishers, 1962. 